2. DE BETEKENIS VAN A. KUYPERS GEMENE GRATIE-LEER VOOR

VANDAG

\title{
J. Douma
}

Hoogleraar, Ethiek en encyclopeadie van de theologie, Theologische Hogeschool, Broederweg 15, 8266 Kampen, Nederland

\section{ABSTRACT}

This article explores the meaning of Kuyper's doctrine of general grace for today, starting off with a consideration of grace and culture from the perspective of three possibilities: grace residing in opposition to, next to or within culture. Calvinism is posited as accepting the last view. The author explores Kuyper's harking back to predestination for a founding of general grace. This bestows meaning on everything, and the author subsequently explores this in more detail, looking at both main trends and byways, and linking specific racial culture (according to Kuyper) very definitely with development. This leads to a consideration of Christendom and technology. This is followed by a critical evaluation of Kuyper's doctrine, in the course of which it is delegated to a nineteenth century vision (in view of subsequent developments), more especially in view of the increasing secularization of the West, in contradistinction to Kuyper's earlier expectations of Calvinist expansion. This is also evident in Kuyper's views of the historical supremacy of the White races. It remains important, however, for the Calvinist to remain within culture, although in the final analysis the first priority should be the gospel of Christ and not the culture of people.

1 Dit artikel werd oorspronkelijk als lezing uitgesproken aan de Universiteit van Potchefstroom op Woensdag 25 September 1985.

-441 -

Koers $51(4) 1986$

ISSN $0023-270 \mathrm{X}$ 


\section{GENADE EN CULTUUR - DRIE MOGELIJKHEDEN}

Wanner wij nagaan hoe christenen denken over de verhouding tussen genade en cultuur, vallen drie mogelijkheden in het oog:

Men kan genade tegenover de cultuur stellen. Genade is iets van Gods wereld, culturur is iets van deze wereld. Met culturele ontplooiing in de politiek, in de wetenschap en in de techniek moet een christen zich zo weinig mogelijk bezighouden. Dat zijn allemaal zaken van déze verdorven wereld, terwijl een christen moet zoeken ùe dingen die boven zijn.

Men kan vervolgens de genade naast de cultuur stellen en naar een neutrale verhouding tussen het 'geestelijk' leven en het 'natuurlijk' leven streven. Er zijn dan twee gebieden waarop de christen zich verschillend kan gedragen. Godsdienst is een zaak van het hart, van de binnenkamer, van het gezin, het persoonlijk en kerkelijk leven Daarbuiten speelt zich het algemeen menselijk leven in al $z$ 'n culturele schakeringen af waaruit men zich niet moet terugtrekken, maar waarin wel andere wetten gelden. De zondag loopt niet gemakkelijk in de maandag over. De christen speelt eigenlijk verschillende rollen in het godsdienstige en niet-godsdienstigen leven. Godsdienst, en dus ook het spreken over de genade van God, moeten we buiten het sociaal-politiek-cultureel leven houden. $\mathrm{Er}$ is geen vijandschap tussen de beide terreinen, maar zij bevinden sich wel náast elkaar.

Er is nog een derde mogelijkheid: de geniade heeft haar plaats in de cultuur. Het leven met Jezus Christus staat niet vijandig tegenover de cultuur en staat er ook niet naast, maar moet in de cultuur gestalte krijgen. Jezus Christus heeft ons als mensen gered, is voor de wereld gekomen en heeft alles onder zijn heerschappij gesteld. De aarde behoort aan de Here, én de volheid darvan (1 Cor. 10:26-28).

Ik hoef hier niet te vertellen dat het calvinisme op het laatstgenoemde van de drie standpunten staat. Calvijn heeft de doperse mijding afgewezen en hij kent geen neutrale gebieden in het leven van de christen. De genade van Jezus Christus breidt zich over het hele leven uit. De verbinding van genade en cultuur is in het voetspoor van Calvijn 
door alle calvinisten beleden, al was de uitwerking van deze verbinding dikwijls verschillend.

Ik vraag Uw aandacht voor een zeer bijzondere uitwerking van de verhouding tussen genade en cultuur, zoals we die bij de nederlandse theoloog Abraham Kuyper - ook in Uw land goed bekend - vinden.

\section{TERUG TOT IN DE PREDESTINATIE}

Een eerste originele trek in Kuypers visio is, dat hij voor de cultuur teruggaat tot in de eeuwige predestinatie. Kuyper maakte bezwaar tegen de gangbare predestinatieleer die hij veel te individualistisch bepaald vond. In de predestinatie, aldus Kuyper, gaat het om meeer dan om het eeuwig behoud of het eeuwig onheil van individuen. Dat mensen zalig worden of verloren gaan, is een aspect van de predestinatie, maar niet het een en het al. Doel van de predestinatie is de zelfverheerlijking van God. Het besluit van de predestinatie omvat de totale historie, het totale verloop dat hemel en aarde nemen zullen, en het is gericht op het doel om uit gans de schepping en uit gans het heelal God zijn eer te doen toekomen.

De zaligheid van de uitverkorenen is belangrijk, maar naast deze lijn onderscheidt Kuyper een tweede lijn in de predestinatie, n.l. de ontwikkeling van de wereld, en dus de ontplooiing van de algemeen menselijke cultuur. De uitverkiezing moet gerealiseerd worden - dat is de eerste lijn-; maar ook de cultuur moet geheel tot ontluiking komen. Als het over de eerste lijn gaat, spreekt Kuyper van de particuliere genade: als het over de tweede lijn gaat, spreekt hij over de algemene genade. $\mathrm{Nu}$ is er tussen de beide soorten van genade een groot verschil. De particuliere genade leidt tot de eeuwige zaligheid voor de uitverkorenen. Vandaar het woord 'particulier' of 'bijzonder'. Maar de algemene genade is er voor alle mensen, die immers allen hun bijdrage aan de cultuur leveren. $Z i j$ is niet zaligmakend. Om misverstand te voorkomen, spreekt Kuyper daarom liever van gemene gratie als het over de algemene genade gaat. Het woordje 'gemeen' geeft aan dat deze gratie voor alle mensen is. Het woordje 'gratie' geeft aan dat het een onverdiend geschenk voor alle mensen is. God had immers na de val van Adam ook heel de mensheid naar de hel kunnen voeren, maar Hij deed $-443-$ 
dat in zijn gratie niet. Adam en Eva bleven leven en hun nageslacht mag onder het schijnen van Gods zon i'n cultuurtaak volbrengen. Dat is gratie, al is het geen genade die eeuwige zaligheid schenkt. Maar door de gemene gratie als algemene gunst van God jegens alle mensen is het wél mogelijk geworden dat de cultuur tot ontwikkeling kwam.

\section{ALLES KRIJGT BETEKENIS}

Met deze visie op de brede predestinatie heeft Kuyper aan alles wat er in deze wereld gebeurd is en nog gebeurt, betekenis willen geven. Ik citeer hem: Het werk van God in de gemene gratie omvat heel het leven van de wereld, het leven onder de Kaffers in Afrika, onder de Mongolen in China en Japan, en onder de Indianen bezuiden de Himmalaya. Er was niets in aile vorige eeuwen onder Egyptenaren en Grieken, in Babylon en Rome, en er is niets nu onder de volken van welk werelddeel ook, of dat alles is noodzakelijk, dat alles vormt een onmisbaar deel van het grote werk dat God werkt, om de wereld in haar ontwikkeling te voleinden. En al is daaronder nog zoveel, waarvan wij niet kunnen inzien, dat het iets met de zaak van het Koninkrijk of met de inhoud van ons geloof van doen heeft, toch heeft dit alles betekenis, en toch kan niets van dat alles gemist worden, omdat het Gode belieft, hetgeen hij bij de schepping in deze wereld had ingelegd, ondanks de Satan en ondanks de zonde van de mens, toch te doen uitkomen, toch door te zetten, en toch zó volkomen te ontwikkelen, dat de volle levensenergie van zijn schepping in de voleinding van de wereld aan het licht zou treden.

Het is Kuyper volle ernst wanneer hij opmerkt dat alles, ook alles in de cultuur een gepredestineerd doel heeft. Wanner hij over de mens als beeld van God spreekt, vraagt hij aandacht voor de sociale zijde van het beeld van God. Dit sociale element betekent dat God bij de schepping van de mens naar zijn beeld een eindeloze menigte van kiemen voor hoge menselijke ontwikkeling in onze natuur heeft gelegd, en dat deze kiemen alleen tot ontwikkeling kunnen komen door het sociale verband van mensen met mensen. De breed vertakte menselijke ontwikkeling, waarin het beeld van God zich op duizendvoudige wijze ontplooit, heeft haar eigen betekenis, ook zonder dat de zaligheid van de mens daarbij van belang is 


\section{DE HOOFDSTROOM EN DE MOERASSEN}

Als alles in de cultuur waarde heeft, omdat we de cultuur vanuit de predestinatie door Kuyper belicht zien, heeft dan alles gelijke waarde? Nee, Kuyper brengt in de ontwikkeling van de cultuur duidelijke gradaties aan. Hij onderscheidt de speciale actie van de gemene gratie en de generale actie van de gemene gratie. De speciale actie is aanwijsbaar buiten de sfeer van die culturen die door het christelijk geloof beïnvloed zijn. Het zijn geïsoleerde culturen, die buiten de bedding lopen waarin zich de hoofdstroom van onze geschiedenis beweegt. Die hoofdstroom laat ons de generale lijn van de gemene gratie zien, omdat we daar de culturen vinden die door Christus beheerst worden.

Ik geef een aantal voorbeelden die bij Kuyper te vinden zijn. Voor de speciale actie van de gemene gratie wijst Kuyper op Mexico en Peru, op India, op China en Japan en op de mohammedaanse wereld. De vrucht vall de gemene gratie was onder die volken overvloedig, maar zij bleef tot die volken self beperkt en kwam niet ten goede aan ons menselijk geslacht als zodanig. Deze gemene gratie staat vroeger of later stil, of loopt zelfs terug en versteent. Zulke culturen kunnen imposant zijn, zoals een meer imposant kan zijn. Maar een meer is toch in zichzelf afgesloten. Het blijven geisoleerde culturen, hoe indrukwekkend de culturen in Mexico, India en Japan ook geweest zijn. Naast meren spreekt Kuyper op een beeldende wijze ook over poelen en moerassen, waar de levensvormen veel lager blijven. Hij Jenkt dan vooral aan Afrika's kust-en binnenlanden, met de culturen van het donker gekleurde ras. Van het nageslacht van Cham - waartoe Kuyper kennelijk alle negers rekent - gaat volgens hem nimmer "een stoot tot hogere levensbezieling" uit. In de profetie van Noach over Sem, Cham en Jafeth ligt naar Kuypers mening de hele wereldgeschiedenis besloten, en voor ons onderwerp betekent dit dan dat het zwart gekleurde ras slechts bij hoge uitzondering tot opvallende ontwikkeling is gekomen. Hottentot en Bosjesman behoren tot een lager ras. In zijn Stonelectures kan Kuyper daarom uitroepen: Ge zijt liever van het Arische ras dan Hottentot of Kaffer! Wie dus op de speciale actie van de gemene gratie let, moet naast de fraaie meren van de Inca-cultuur en de Maya-culturen ook kijken naar de miserabele poelen en moerassen die de zwarte culturen te zien geven. 
Totaal anders is het met de generale actie van de gemene gratie. Want daar wordt de gemene gratie door de bijzondere genade bevrucht. Het voorspel ervan loopt via de culturen van Babylon, Egypte, Griekeland en Rome, die de basis leggen voor wat de hoofdstroom van de wereldcultuur gaat worden: de cultuur zoals zij door de bijzondere genade van Jezus Christus een stempel op heel de wereldgeschiedenis zal zetten. Hier gaat het niet meer om een meer, hoe fraai ook, maar om een geweldig bruisende stroom die door de wereld slingert. De gemene gratie krijgt een exponent en wordt verdriedubbeld in kracht, zoals Kuyper zegt. De grote macht die in het gechristianiseerde deel van de wereld, met name op technisch terrein, in de vorige eeuw ontwikkeld is, ziet Kuyper als vrucht van het christelijk geloof. De natuurkundige wetenschappen zijn niet tot bloei gekomen in China of Japan, in Indië of Turkije, maar in het christelijke Europa en het christelijke Amerika. Japan had zich in de dagen van Kuyper ook reeds tot een grote macht ontwikkeld, maar - zegt Kuyper, Japan bootst ons na. Het technisch vermogen van de Japanner gaat terug op europese en amerikaanse ontdekkingen, die op hun beurt hun oorsprong vinden in de gemene gratie zoals deze gratie door de arbeid van Christus verrijkt is. Het is de hoogste vorm van de gemene gratie omdat zij met de particuliere genade samenvloeit!

\section{CHRISTENDOM EN TECHNIEK}

De grote opbluei van met name de techniek heeft Kuyper ook met bijbelse gegevens willen funderen. Als we op Christus wondermacht letten, warmee hij zieken heeft genezen, broden heeft vermenigvuldig en de zee tot bedaren heeft gebracht, dan moeten we volgens Kuyper niet direct aan Christus goddelijke natuur denken om dit te begrijpen. We moeten Christus hier zien als de herstelde mens, die weer kon wat Adam zou hebben gekund als hij niet in zonde gevallen was. Als nieuwe mens heeft Christus macht over de natuurkrachten ontvangen, en wie in het voetspoor van Christus gaat, ontvangt soortgelijke macht, zodat hij de wereld technisch op een wonderbaarlijke wijze kan ontsluiten. Kuyper citeert daarvoor de tekst Joh 14:12: Voorwaar, voorwaar, Ik zeg u, wie in mij gelooft, de werken die ik doe, zal hij ook doen; en hij zal grotere werken doen. Welnu, dat heeft betrekking op de techniek, aldus Kuyper. 
Het koningschap van de mens, dat in Jezus als de Zoon van de mens opleefde, straalt in zijn gelovigen uit. De vrije christen is geen slaaf meer van de natuur, heeft geen angst meer voor de natuur, vereert geen bodem, bomen en bossen meer als heilige zaken, maar durft de wereld te ontginnen en te ontplooien. Door de kracht van de bijzondere genade heeft de gemene gratie in haar hoofdstroom van de wereldcultuur de schitterende techniek kunnen ontwikkelen die we in Europa en Amerika kunnen vinder,. In het christendom komt de cultuur tot $z$ 'n hoogste bloei, want daarin vloeien de gemene gratie en de particuliere genade samen.

\section{KUYPER EN DE KAAPSE BOEREN}

Ik moet $u$ zeggen dat ik in mijn studententijd nogal kritisch over Kuyper oordeelde. Ik groeide op in een kerkelijke gemeenschap die Kuypers leer over verbond en doop en zijn opvattingen over de pluriformiteit van de kerk afwees. Dat zijn inderdaad zwakke punten in Kuypers theologie. Maar toen ik bezig ging met mijn dissertatiestudie over Kuypers gemene gratie, ben ik diep onder de indruk gekomen van zijn cultuurbeschouwing. I $k$ heb Kuypers driedelige serie 'De gemeene gratie' en ook zijn driedelige uitgave 'Pro Rege' verslonden. En ik zeg precies hetzelffe als wat prof. dr. A.A. van Ruler eens heeft geschreven: $\mathrm{Er}$ zal kritiek te leveren zijn op Kuypers idee van de ene stroom tegenover de vele meren en poelen, evenals op zijn idee van de dominerende betekenis van het christendom in de europees-amerikaanse cultuurkring. Maar dit nu even daargelaten, wat een zeldzaam grootse apologie heeft Kuyper geleverd voor de absolute en universele betekenis van het christendom! Welk een schitterende oplossing heeft hij gegeven van de verhouding van gemene gratie en particuliere genade! Men moet bewondering hebben voor de brede allure, de grote denkkracht de stoute durf van deze geschiedeniswijsgerige constructie, gezien in het verband met de dogmatische en cultuurtheoretische problemen van de christelijke-cultuur-idee. Er light iets ongemeen fascinerends in, aldus Van Ruler.

Ik kan eraan toevoegen dat de idee die Kuyper in zijn gemene-gratie-leer ontwikkeld heeft, geen studeerkamerwijsheid voor hem bleef, maar realiteit in zijn leven had. Kuyper was de oprichter van de Vrije Universiteit, en in deze Universiteit, gesticht in 1890, 2 ag hij een 
krachtcentrale voor de christelijke cultuur. Hij geloofde dat er in het calvinisme potenties verborgen waren die in het europese westen, in de Verenigde Staten en ook in uw land tot ontwikkeling dienden te komen, en dat dit een nieuwe opbloel van het culturele leven tot gevolg zou hebben. Kuyper was niet alleen theoloog, maar ook strateeg. De Vrije Universiteit zou leiding geven aan die ontwikkeling van het culturele leven, en dan niet alleen in Nederland, maar met een zo wijd mogelijke actie-radius. Kuyper heeft geloofd in de kracht van het calvinisme, zoals hij dat tot nieuw ontwaken zag komen in zijn eigen land, in Amerika en in Zuid-Afrika. In de trek van de Kaapsé Boeren zag Kuyper een macht die door God gewekt was en die heel de toekomst van Afrika zou beheersen.

\section{EEN VEROUDERDE VISIE OP DE ZWARTE MENS}

Wanneer $u$ mij nu vraagt wat de betekenis van Kuypers gemene-gratie-leer voor vandaag is, dan moet ik allereerst zeggen dat op deze leer het stempel van de negentiende eeuw staat. Dat stempel staat erop wanneer we aan Kuypers visie op de techniek letten. Alles is nog in bruisende ontwikkeling in zijn dagen, terwijl wij veel meer oog gekregen hebben voor de bedenkelijke ontwikkeling die aan de technische ontplooiing verbonden is. Niet lang nadat ik mijn dissertatie voltooid had, kwam b.v. via het Rapport van de Club van Rome scherp voor onze aandacht te staan dat de mens met zijn techniek ook uitbuiter van deze wereld is geworden. Roofbouw, verontreiniging van het milieu, verkwisting van de grondstoffen, riepen als vanzelf vragen op over onze cultuuropdracht. Een groot deel van het menselijk technisch vernuft wordt gebruikt voor het ontwikkelen van nucleaire wapens met vernietigende kracht voor heel de mensheid. Technische ontwikkeling zonder ineer is nog geen positieve zaak. Dat wist Kuyper natuurlijk ook wel; maar omdat onze tijd dat nog scherper laat zien, is het $\mathrm{m}$.i. voor ons ook niet mogelijk om Joh. 14:12 op de ontwikkeling van de techniek toe te passen. De grotere werken warrover Jezus spreekt, zijn de werken die zijn volgelingen in prediking en wondermacht mogen verrichten, en die een geweldige bekering onder de mensen tot stand zullen brengen. De techniek kan schitterende dingen verrichten, maar zij kan de wereld ook in een vuilnisbelt of puinhoop veranderen. 
Het stempel van de negentiende eeuw staat ook op Kuypers ideeën wanneer we aan zijn optimisme denken over de ontplooiing van het calvinisme. Niet het calvinisme, maar de secularisatie heeft triomfen beleefd in West-Europa, in de Verenigde Staten, en - naar ik meen - ook in Zuid-Afrika. Er is minder kracht uitgegaan van het calvinisme dan Kuyper verwacht heeft. Ik denk hier ook aan de Vrije Universiteit van Amsterdam, die voor zoveel christelijke wetenschappers in de wereld van grote betekenis is geweest. Deze Universiteit heeft echter haar calvinistisch karakter volledig verloren. Van een krachtcentrale voor het calvinisme valt niet meer te spreken. Nog in een ander opzicht is het duidelijk dat Kuypers gemene-gratie-leer uit de vorige eeuw stamt. $\mathrm{Hij}$ is niet alleen onder de indruk van de positieve betekenis van de techniek en van de superioriteit van het calvinisme, maar hij gelooft ook nog in de superioriteit van het blanke ras als een blijvende factor in de wereldgeschiedenis. De zwarte mens kan hij alleen maar zien als afstammeling van Cham en daardoor als dienstknecht van Sem en Japheth. Exegetisch is dit al een vreemde zaak, want de vervloekte zoon van Cham is Kanaan $(G e n .9,25)$. Bij deze naam kunnen we denken aan de bewoners van Kanaan ten tijde van Israëls intocht in het land Kanaan. Het gaat dan over bewoners van het gebied langs de Middellandse Zee tot Libanon en niet over zwarte mensen. Aan de naam van Cham zijn in Genesis 10 de namen van Kanaan en ook van Nimrod verboden. En wie Nimrod noemt, moet - blijkens Genesis 10 - ook die culturen van Babel, Akkad en Ninevé noemen. Dat zijn geen lage en minderwardige culturen geweest.

De veroordeling van Cham in Kanaan is een religieuze veroordeling en geen veroordeling tot culturele minderwaardigheid. De Bijbel leert daarover niets. Wie aan zwarte mensen in de Bijbel denkt, kan geen associaties leggen tussen zwart en minderwaardig. zoals Kuyper dat deed. Mozes trouwde met een Ethiopische vrouw (Num.12:1); de Ethiopische Sabeeërs worden van hoge gestalte genoemd (Jes.45:14), en ook de Ethiopische staatsambtenaar van Kandacé uit Handelingen 8 was een cultureel gevormd mens. Kuyper kon alleen spreken zoals hij deed, omdat hij nog in de dagen van het kolonialisme leefde, waarin de afschaffing van de slavernij nog maar nauwelijks aanvaard was. Wij leven al weer ruim tachtig jaar na de publikatie van Kuypers driedelig werk De Gemene Gratie', en wij zien duidelijker dan hij dat het tijdperk van het -449 - 
kolonialisme of van de daarmee samenhangende superioriteit van het blanke ras in de relatie van baas en knecht tot alles wat gekleurd is onder de mensen, voorbij is.

\section{KUYPER DROOMDE EEN DROOM}

$U$ hebt opgemerkt dat ik het moeilijk vind Kuypers leer van de gemene gratie voor vandaag nog só te aanvaarden als ze door hem is ontworpen. Ik heb enkele problemen genoemd, ik zou er nog meer kunnen noemen. $U$ kunt ze vinden in mijn studie 'Algemené genade'. Ik wil nu - ondanks alle kritiek die er uit te brengen is op Kuypers leer - de aandacht vragen voor het feit dat Kuyper als een echte calvinist de genade van Jezus Christus in de cultuur heeft geplatst. Hij is de man geweest die, de calvinisten heeft opgeroepen sich met politiek, met het onderwijs, met de wetenschap, met de pers, met de kunst en met welke andere cultuuruiting bezig te houden. Prof. Herman Ridderbos heeft eens treffend opgemerkt dat Kuyper de mensen verzamelde die tussen het pakgoed waren weggekropen, zoals Saul voor Samuël was weggekropen toen hij koning moest worden! Welnu, wij moeten niet wegkruipen. Wij moeten dat ook niet doen nu de dreiging van de nucleaire technische vernietigingsmogelijkheden boven ons hoofd hangt, nu de secularisatie sterker blijkt dan het calvinisme en nu blanken naast zwarten moeten leven in een maatschappij die steeds meer gaat integreren. De genade van Jezus Christus moet in de cultuur en niet daarbuiten komen. Zij is een zaak van heel ons leven. Kuyper zei bij de opening van de Vrije Universiteit: $E r$ is geen duimbreed op heel het erf van ons menselijk leven waarvan de Christus, die aller Souverein is, niet roept: Mijn! Dat moet ook onze betijdenis zijn.

Kuyper droomde een droom; maar ook al is zijn droom niet uitgekomen, zijn belljdenis van het christelijk geloof als een zout van de wereld, moet onze belijdenis blijven.

Alleen - wij zullen meer bescheiden moeten spreken over de invloed, die de christen op deze wereld kan hebben, dan Kuyper het deed. De genade moet in de cultuur haar plaats hebben, zeker, maar wij belijden ook met Petrus en anderen dat wij vreemdelingen in deze wereld zijn. Wie $-450-$ 
vandaag Kuyper waardeert, moet toch ook weer terug naar wat Calvijn in zijn institutie over de vreemdelingschap van de christen zegt in de beroemde passage 'de vita christiana'. De christen is in deze wereld, de wereld van Jezus Christus, wèl op $z$ n plaats - hij heeft hier een roeping: maar de christen is hier niet thuis. Wel op $z$ in plaats, en toch niet thuis - in deze korte formulering vat ik Kuyper en Calvijn samen. Het evangelie moet doorwerken op alle levensterreinen, mar het stuit op zoveel verzet dat de hele geschiedenis ook getekend kan worden onder het beeld van de vrouw in de woestijn (Openb.12). De kerk predikt op de straten van die stad, maar zij wordt niet geaccepteerd. Vervolging is haar deel; zij weet dat zij vreemdeling hier beneden is. In een woestijn liggen oases en zo zijn er ook in de geschiedenis perioden aan te wijzen waarin het evangelie voor veel volken inderdaad ook christelijke cultuurontplooiing meegebrincht heeft. Wie Kuypers geschiedbeschouwing van het paradijs tot aan zijn eigen tijd volgt, zal op tal van punten van harte met hem instemmen als het over de bijzondere genade in haar betekenis voor de mensheid gaat. Hij zal ook dankbaar zijn voor wat de Reformatie, en dan in het bijzonder het calvinisme aan de voortgang van de geschiedenis heeft bijgedragen.

Maar toch moeten we niet vergeten dat oases in de woestijn liggen. Ik zie met dankbaarheid terug op mijn eigen vaderlandse geschiedenis waarin kerk en cultuur zo dikwijls op elkaar hebben ingewerkt. $U$ zult dat in Uw eigen geschiedenis kunnen aanwijzen. Maar én in Nederland én in Zuid-Afrika moeten de calvinisten sich niet blindstaren op het verleden. Wij kunnen danken voor wat we ontvangen hebben; we moeten leren van de fouten die we gemakt hebben, en we moeten vooral vastberaden, maar ook bescheiden verder werken in een nieuwe tijd onder omstandigheden die meer aan de woestijn dan aan een oase doen denken.

Wij zijn hier op onze plaats, en daarom moeten we ons niet terugtrekken uit de cultuur. We zijn hier niet thuis, en daarom moet het ons niet verbazen wanneer oaseperioden voorbijgaan en de kerk beproefd gaat worden. Dan zal ook blijken of de kerk werkelijk kerk is, en dus of zij het evangelie zuiver en met het oog op de concrete situatie verkondigt. Zij kan b.v. niet in verouderde ideeën over rassen geloven zoals Kuyper nog geloofde, maar zij moet het woord van God duidelijk en moedig verkondigen, desnoods tegen de overheid in, wanneer discriminerende 451 . 
wetten worden uitgevaardigd of gehandhaafd. Het is jammer dat de wereld soms een scherper oog heeft voor onrecht dan de kerk en dat de kerk met het evangelie, dat haar is toebetrouwd, of niet of te laat komt.

\section{DE CULTUUR WINNEN EN HET EVANGELIE VERLIEZEN}

Want in de verkondiging van het evangelie zijn we met de eerste taak bezig die ons allen is opgedragen. We lezen dat het evangelie van het koninkrijk in de hele wereld gepredikt moet worden en dat dan het einde komen zal (Matth.24:14). Kuyper zette daar iets naast. Hij zei dat alles wat God in de natuur en in de wereld verborgen had, allemaal aan het licht moest treden. en dat dan het einde komen zal. Geen einde van de geschiedenis voordat het evangelie in de hele wereld gepredikt is, zegt de Bijbel. Geen einde van de geschiedenis voordat uit de wereld gehaald is wat er inzit, zegt Kuyper ernaast.

Ik weet niet of we die twee zo naast elkaar kunnen zetten. In elk geval geeft de Bijbel geen steun aan die gedachte, al zegt dat nog niet dat de bijbel die gedachte zou bestrijden. Maar wie de christelijke cultuur meer als een oase dan als een continue factor in de wereldgeschiedenis ziet, zal weten wat het eerste is wat hij als zijn taak moet zien: Eerst de prediking van het evangelie; zoek eerst het koninkrijk van God. En dan kan het gebeuren dat christelijke cultuur in het gevolg van deze prediking meekomt. Niet als een continue factor in de wereldgeschiedenis, wel als een geschenk van God, als een oase voor de kerk in de woestijn.

Ik heb bestudeerd voordat ik naar Zuid-Afrika gekomen ben wat Kuyper over Uw positie in de wereldgeschiedenis gezegd heeft. Hij heeft dan dikwijls zeer lovende woorden voor $U w$ geschiedenis. Hij ziet $U$ opgenomen in de hoofdstroom van de geschiedenis warin de gemene gratie bevrucht wordt door de particuliere genade. Maar hij schrijft in het derde deel van Pro Rege ook: Wie de houding van onze Christenboeren in Zuid-Afrika tegenover de negers nagaat, voelt, hoe ook onder de Boeren de hoge drang, om deze stammen voor de Christus te winnen, om niet meer te zeggen, althans veel te zwak sprakl De protestantse koloniale mogendheden - en Kuyper denkt dan ook aan Nederland hebben een groot deel van de drie eeuwen die achter de twintigste eeuw 
liggen, verspeeld en de drang van de hartstocht niet gekend am de eer van Christus ten volle in de heidense en mohammendaandse streken te doen doordringen.

Dat zijn eerlijke woorden van een man die zijn eigen vaderland en ook Zuid-Afrika liefhad. I $k$ kan het vandaag in vraagvorm ook aldus zeggen: Hebben wij onze eigen cultuur en onze eigen geschiedenis als christelijke cultuur en christelijke geschiedenis niet zó gekoesterd, dat we lijken op de gemeente van Laodicea, waarin men zei: "lk ben rijk en ik ben verrijkt geworden en heb aan niets gebre:" (Openb.3:17)? We zijn dan zó met onszelf bezig dat we geïsoleerd raken en niet meer als zout van de aarde functioneren. We hebben de cultuur gewonnen, maar het evangelie verloren. We willen uit de wereld halen wat erin zit voor onszelf, maar we vergeten wat de eerste roeping is: het evangelie aan alle volken verkondigen. De bestudering van Calvijn, maar ook van Kuyper, kunnen ons duidelijk maken dat de cultuur die wij opgebouwd hebben, ons bij de handen afbreekt - niet alleen ondat de wereld vijandig tegenover ons staat, maar ook ondat wij zelf nalatig zijn geworden in onze eerste roeping. ${ }^{2}$

2 Voor literatuur verwijs ik naar A. Kuyper, De Gemeene Gratie (3 dln), Kampen z.j. en Pro Rege (3 din), Kampen 1911-1912. Uitvoeriger heb ik over Kuypers gemene-gratie-leer geschreven in mijn boek Algemene genade 4, Goes 1981. Daarin kan men ook de mening van A. A. van Ruler terugvinden. Voor de citaten over (Zuid-)Afrika, zie de Gemeene Gratie 1,92.296v; 11,411 (over de vloek van Cham); 1,306 (over de Kaapse Boeren): Het Calvinisme (Stone!ezingen), Kampen z.j., 179 en Pro Rege III,315v. 